\title{
Pain patients and who they live with: A correlational study of coresidence patterns and pain interference
}

\author{
Jacob M Vigil PhD ${ }^{1}$, Patricia Pendleton $\mathrm{BSN}^{2}$, Patrick Coulombe $\mathrm{MS}^{1}$, Kevin E Vowles $\mathrm{PhD}^{1}$, \\ Joe Alcock MD ${ }^{1}$, Bruce W Smith PhD ${ }^{1}$
}

JM Vigil, P Pendleton, P Coulombe, KE Vowles, J Alcock, BW Smith. Pain patients and who they live with: A correlational study of coresidence patterns and pain interference. Pain Res Manag 2014;19(4):e109-e114.

BACKGROUND: Mixed associations have been observed between various aspects of 'social support' and patient pain experiences.

OBJECTIVE: To explore the possibility that more basic social factors, namely coresidence patterns, may be associated with variability in patient pain experiences.

METHODS: Relationships between coresidence partners and selfreported pain that interferes with activities were examined in a large representative sample of home health care patients ( $n=11,436$; age range 18 to 107 years, mean $[ \pm \mathrm{SD}]$ age $66.3 \pm 16.1$ years; $55 \%$ females).

RESULTS: After controlling for sex, age and behavioural risks, compared with living alone, coresidence with an intimate affiliate (eg, spouse, relative) predicted greater pain interference (Cohen's $d=0.10$ to 1.72 ), and coresidence with a less intimate type of affiliate (eg, friend, paid help) predicted lower pain interference (Cohen's $d=-0.21$ to -0.83 ). In general, however, coresidence patterns accounted for small proportions of variance in pain interference, and the magnitudes of these effects varied widely according to patients' sex, age and diagnosis.

DISCUSSION: The findings suggest that fundamental components of patient's home-living environment may be associated with potential costs and benefits related to clinically relevant pain functioning for some subgroups of patients.

CONCLUSION: Further research that incorporates quantitative and qualitative assessments of patient pain functioning is warranted to better understand how objective and subjective characteristics of patients' homeliving environment may inform the development of more individualized pain treatment options for patients with differing social circumstances.

Key Words: Epidemiology; Home care; Pain signalling; Sex; Social determinants of

$\mathrm{T}$ he considerable amount of research examining the associations between various aspects of 'social support,' social contact and core components of the pain experience, including how pain interferes with activities, has produced mixed findings $(1-10)$. A large body of literature suggests that a lack of social connectedness is a mortality risk factor in line with other major health risks such as smoking and obesity (11). However, higher levels of pain-related solicitous behaviours from significant social partners have been linked to heightened pain reports (12-20). Similarly, experimental research shows that the mere presence of a same-sex friend increases self-reported pain sensitivity, particularly among women (21), whereas the presence of strangers has been shown to decrease pain sensitivity, particularly among men (22). It may, therefore, be helpful that distinctions are made between one's available (having access to) social support and actual interaction with others, a more functional aspect of social support, which is clinically important for understanding how different types of social experiences and home-living conditions may influence patient prognoses.

The findings of the effect of social interactions on pain are broadly consistent with a social signalling perspective of human pain

\section{Les patients souffrant de douleurs et les personnes avec qui ils habitent : une étude corrélationnelle des profils de corésidence et d'interférence avec la douleur}

HISTORIQUE : On a observé des associations mixtes entre divers aspects du « soutien social » et les expériences de douleur des patients. OBJECTIF : Explorer la possibilité que des facteurs sociaux plus fondamentaux, notamment les profils de corésidence, puissent s'associer à une variabilité dans les expériences de douleur des patients.

MÉTHODOLOGIE : Les chercheurs ont examiné les relations entre les partenaires de corésidence et la douleur autodéclarée qui nuit aux activités dans un grand échantillon représentatif de patients en soins à domicile ( $\mathrm{n}=11$ 436; fourchette d'âge de 18 à 107 ans, moyenne [ \pm ÉT] de $66,3 \pm 16,1$ ans; $55 \%$ de femmes).

RÉSULTATS : Après rajustement compte tenu du sexe, de l'âge et des risques comportementaux, par rapport à vivre seul, la corésidence avec un proche (p. ex., conjoint, membre de la parenté) était prédictive d'une plus grande interférence avec la douleur ( $\mathrm{d}$ de Cohen 0,10 à 1,72) et la corésidence avec une personne moins proche (p. ex., ami, aide rémunérée), d'une interférence plus faible avec la douleur ( $\mathrm{d}$ de Cohen $-0,21$ à $-0,83$ ). Cependant, en général, les profils de corésidence représentaient une faible proportion de la variabilité de l'interférence avec la douleur, et l'importance de ces effets variait considérablement selon le sexe, l'âge et le diagnostic des patients.

EXPOSÉ : D’après les résultats, les aspects fondamentaux du milieu de vie à domicile du patient pourraient s'associer à des coûts et avantages potentiels pour certains sous-groupes de patients, liés au fonctionnement de la douleur pertinent sur le plan clinique.

CONCLUSION : D'autres recherches qui intègrent des évaluations quantitatives et qualitatives du fonctionnement de la douleur du patient s'imposent pour mieux comprendre en quoi les caractéristiques objectives et subjectives de l'environnement du patient à domicile peuvent étayer la préparation de traitements contre la douleur plus personnalisés chez des patients qui vivent dans diverses situations sociales.

behaviours (23-28). From this perspective, the reciprocal influence of pain perception and pain empathizing reactions of others can be framed as a symbiotic transactional process in which pain behaviours are heuristically used to signal vulnerability cues to the types of affiliates who are most likely to provide reliable and remedial assistance to the individual experiencing pain (29). This operant thesis is presented in Figure 1, which broadly describes how the frequency of interactions with more or less intimate (time-invested and familiar) affiliates are expected to covary with greater and lesser clinical pain experiences, respectively. Women tend to form more intimate interpersonal relationships (26) and demonstrate higher pain empathizing behaviours than men (22), and the degree of intimacy that men share with their significant other (eg, marital status) has been shown to be associated with differential pain reports (30). Other findings show that dynamic psychosocial constructs, such as the degrees of emotional and logistical support from one's significant other, are associated with differential pain sensitivity in men and women (31). What is currently unknown is whether even more fundamental, objective and easily measurable components of patients' home-living environments, including the

${ }^{1}$ University of New Mexico, Albuquerque, New Mexico; ${ }^{2}$ Baptist Medical Center, Jacksonville, Florida, USA

Correspondence: Dr Jacob M Vigil, Department of Psychology, University of New Mexico, 1 University of New Mexico, MSC03 2220,

Albuquerque, New Mexico 87131-1161, USA. Telephone 505-277-0374, e-mail vigilj@unm.edu 


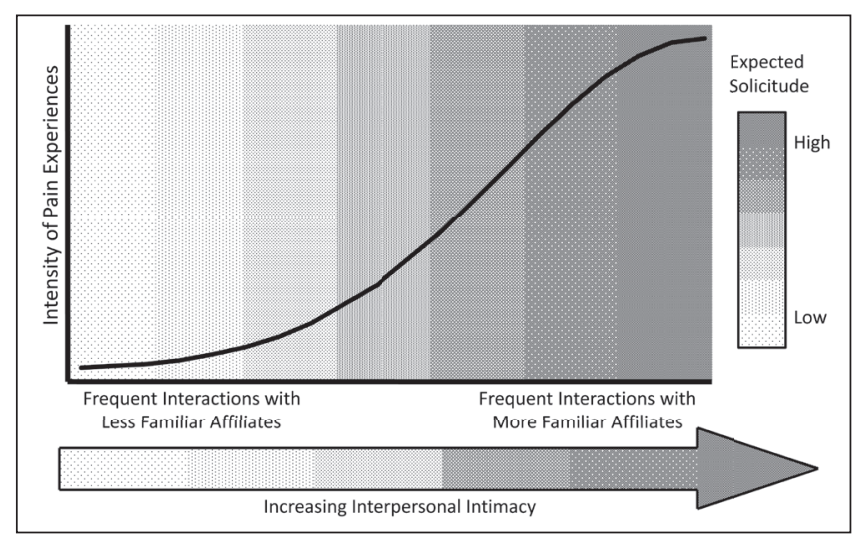

Figure 1) Social-signalling model of the influence of social environmental factors on the intensity of clinical pain experiences. Pain intensity is predicted to increase with more frequent interactions with intimate and familiar affiliates because these affiliates are most likely to express solicitous reactions toward the individual experiencing pain

broad types of relationships that patients share with their coresidents, are associated with variability in clinically relevant pain. A better understanding of how objective and subjective social factors influence patient pain experiences is important for informing the development of more individualized treatment options for patients living under differing social circumstances.

The current study involved a large representative sample of home health care patients to address this absence in the extant literature. On the basis of the social-signalling model described above, and based on previous research among chronic pain patients, we explored the hypothesis that patients who coreside with more intimate types of relationship partners, such as a significant other (eg, in comparison with living alone or living with paid help), and especially male patients who presumably live with pain-empathizing females, will report higher pain interference. These effects were analyzed among the entire sample of home health care patients as well as for patients with different primary diagnoses to determine whether the patient's particular medical condition may affect any potential associations between coresidence patterns and activity-interfering pain.

\section{METHOD}

\section{Participants}

Data were obtained from the medical records of patients using home health care services from a large home health care agency that services five urban and rural counties within a state in the Southeastern United States from 2005 to 2009. The data had already been collected as part of normal patient services protocols, and patients provided consent for their information to be used for medical (eg, diagnostic) purposes on admission. In total, the sample consisted of 11,436 home health care patients (age range 18 to 107 years, mean [ \pm SD] age $66.3 \pm 16.1$ years; $55 \%$ females). Patients were clustered according to primary diagnosis and separate analyses were performed for the patient subgroups with the most commonly represented diagnoses. For these analyses, at least 90 individuals were required to be included within each diagnostic category to be able to compare modest samples $(n>30)$ of male and female patients. Diagnostic categories were identified according to the International Classification of Diseases, Ninth Revision (ICD-9). The subgroups included ICD-9 codes 250.00 (diabetes $[n=206]), 401.90$ (essential hypertension [ $n=287]), 414.00$ (chronic ischemic heart disease [ $n=562]$ ), 427.31 (atrial fibrillation $[n=209]$ ), 428.00 (congestive heart failure $[\mathrm{n}=314]$ ), 434.91 (cerebral artery occlusion $[n=168]), 443.9$ (peripheral vascular disease $[n=96])$, 453.90 (deep vein thrombosis $[n=101]$ ), 486.00 (pneumonia $[n=261]$ ), 496.00 (chronic airway obstruction [n=201]), 599.00 (disorders of urethra $[n=133]$ ), 682.60 (cellulitis and abscess of leg $[n=190]$ ),
715.90 (osteoarthrosis $[\mathrm{n}=230]$ ), 728.87 (general muscle weakness [ $\mathrm{n}=508]$ ), 780.20 (syncope and collapse, fainting, blackout $[\mathrm{n}=127]$ ), 781.20 (abnormality of gait $[\mathrm{n}=381]$ ) and 998.83 (nonhealing surgical wound $[\mathrm{n}=124])$.

\section{Procedures}

Data were collected using the Centers for Medicare and Medicaid Services' Outcome and Assessment Information Set (OASIS) version B1, which is specifically designed for use in home health care patients and is mandated by Centers for Medicare and Medicaid Services as a Condition of Participation for beneficiaries that are reimbursed by Medicare and/or Medicaid (32). The OASIS was completed and recorded by registered nurses or rehabilitation therapists for all adult nonmaternity patients receiving skilled services at the time of admission to the home health care agency. This was performed by asking patients to respond to individual questions, and the patient-generated responses were combined with diagnostic information (eg, ICD-9 codes) from the patients' medical records. The patient-generated responses were documented by the home care clinical staff at point of care into an electronic format with the instructions to "mark all (responses) that apply." For each item, the home care clinicians verbally provided the response options to the patient and recorded the patient's exact responses. Thus, the data are representative of patient-generated information and patient conditions before receiving the home care services, which is important for the current study because it precedes the potential impact of health care providers' treatment recommendations, which may include adjustments in patients' living arrangements (eg, suggested caregiver arrangements).

\section{Measures}

The OASIS comprehensive assessment has been shown to be a reliable and valid measure of functional domains of patient health status (33). The OASIS consists of 106 items for measuring patient-provided demographic and health care history, living arrangements, and a broad range of areas about patient health status and functioning. The current study examined the core set of questions pertaining to the occurrence and extent of pain interference, primary patient diagnosis, demographic characteristics (ie, sex and age) and coresidence patterns. In addition, behavioural risk factors (heavy smoking, obesity, alcohol dependency and drug dependency) were recorded and examined along with the demographic and diagnostic variables as potential covariates to the primary variables of interest (eg, coresidence patterns and pain interference).

The item that asked patients to indicate their "frequency of pain interfering with their (the patient's) activity or movement" was measured on a four-point ordinal scale (coded 0 to 3 ) with the response options: $0=$ no pain, or pain does not interfere with activity or movement; 1 = less often than daily; 2 = daily, but not constantly; or 3 = all the time. Overall, 8045 patients $(70.3 \%)$ scored $\geq 1$ on this item, indicating some degree of pain interference. Of these patients, $9.8 \%$ reported pain interference less than daily, $50.6 \%$ daily and $10.0 \%$ constantly.

Patients' cohabitation was recorded by asking participants to describe all the people the patient lives with. The coresidents were coded across six categories: alone, with a significant other, other family member, friend, paid help (other than home care medical staff) and/or other person(s). When the patient lived with more than one person, only patients' most closely related/most intimate types of housemates were considered for the present analyses.

Additional variables included the health risk behaviours of heavy smoking, obesity, alcohol dependency and drug dependency. Patients were asked to "indicate any of these behaviours that the patient felt was likely to affect current health status and or outcome." The presence of a risk factor in either the present or past, according to patient reports or chart records, was coded 0 (absence of risk) or 1 (presence of one or more risks). 


\section{Statistical analysis}

Parametric analyses were conducted using the four-level pain interference measure as the primary outcome variable. Thus, patients who reported no pain interference were included in the models to measure the likelihood of experiencing pain interference rather than the degree to which pain affects patients with chronic or debilitating pain. Coresidential patterns were dummy-coded, with the absence of a coresidential partner (ie, lives alone) as the reference category. Multivariate regressions were used to examine the relationships among the main predictor variables (relationships with cohabitants and sex) and frequency of pain interference, while controlling for the covariates (age and behavioural risk). Effect-sizes were estimated using Cohen's d (mean difference/mean SD [34]). Where appropriate statistically, age was considered as either a continuous or categorical variable using tenyear increments (ie, $<30$ years of age, 30 to $<40$ years of age, 40 to $<50$ years of age, etc, to $>90$ years of age)

\section{RESULTS}

\section{Coresidence patterns}

To examine the unique contribution of patient's relationships with their coresidents to the degree of pain interference that patients reported, a hierarchical multiple-regression analysis was first performed. Variables that explain pain interference were entered in two steps. In step 1, pain interference was the dependent variable and Sex, Age and Behavioural Risk were the independent variables. In step 2, the dummy codes for the Housemate variable (lives with a significant other, other family member, friend, paid help or other person, and with living alone as the reference group) were entered into the step 1 equation. The results of step 1 indicated that the variance accounted for $\left(\mathrm{R}^{2}\right)$ by the first three independent variables (Sex, Age and Risk) equaled 0.038 (adjusted $\mathrm{R}^{2}=0.037$ ), which was significantly different from zero $(\mathrm{F}[3,10852]=141.29 ; \mathrm{P}<0.001)$. The strongest predictor of pain interference was younger age $(\beta=-0.15, \mathrm{P}<0.001)$, followed by reporting a behavioural risk $(\beta=0.09 ; \mathrm{P}<0.001)$, and being female $(\beta=0.05 ; P<0.001)$. In step 2 , the five dummy codes for the Housemates variable were entered into the regression equation. The change in variance accounted for $\left(\Delta R^{2}\right)$ was 0.002 , which was significantly different from zero $(F[5,10844]=4.79 ; \mathrm{P}<0.001)$. Controlling for covariates in the full model, there was a slight group difference in pain interference between patients who cohabitate with a significant other and those who live alone $(\beta=0.03 ; \mathrm{P}=0.018)$ and, by comparison, a slight difference in the opposite direction between patients who cohabitate with paid help and those who live alone $(\beta=-0.02$; $\mathrm{P}=0.037$ ). As shown in Figure 2, using a Bonferroni correction for multiple comparisons $(\mathrm{P}<0.01)$, analyses conducted among the entire sample without considering age, sex and behavioural risk revealed that living alone predicted slightly higher pain interference than cohabitating with paid help and slightly lower pain interference than cohabitating with a significant other (as was the case when controlling for age, sex and risk).

To examine whether the coresidence patterns and pain interference were moderated by sex of patients, terms for the Housemate $x$ Sex interaction were computed, yielding five interaction terms (five terms for Housemate by one term for Sex). All five interaction terms, along with the housemate terms, sex, age and behavioural risk, were included in a regression analysis with pain interference as the outcome variable.

This analysis $\left(R^{2}=0.041\right)$ revealed a trend for a significant coresidence with a Significant Other $\times$ Sex interaction term $(\beta=-0.06$; $\mathrm{P}=0.011$ ), indicating that the predicted difference between patients who live with a significant other and those who live alone, controlling for age, sex and risk, is slightly different for male and female patients. Follow-up analyses regressing pain interference on the housemate category pertaining to one's significant other, conducted separately for male and female patients (controlling for age and risk), revealed a significant difference in predicted pain frequency between male patients who live with a significant other and those who live alone; male patients living

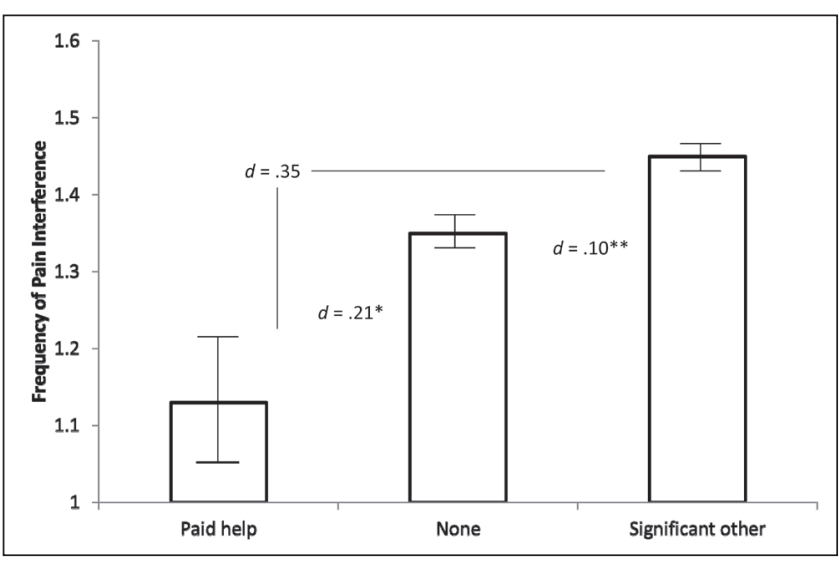

Figure 2) Mean pain interference scores for patients who live with a significant other, alone or with paid help. $* P<0.01 ; * * P<0.001$

with a significant other reporting slightly more pain interference than male patients living alone $(\beta=0.07 ; \mathrm{P}=0.001, \mathrm{~d}=0.13)$. By comparison, no such difference was found among female patients $(\beta=0.01 ; P=0.447)$.

To examine whether the relationships between coresidence patterns and pain interference varied according to patient age, separate equations were run entering the residence categories $(\mathrm{k}-1)$ as predictor variables for male and female patients, separately, in different age ranges (in 10-year increments) while controlling for age and behavioural risk. Group comparisons were only conducted among cell sizes with $>25$ patients (inadequate sample sizes prevented analyses for patients $<30$ years of age). These analyses revealed particular group differences in pain interference between patients who live alone and those who cohabit with a significant other for men in their 30s $\left(\beta=0.26 ; P=0.023, d=0.51, R^{2}=0.056\left[\Delta R^{2}=0.046 ; P=0.084\right]\right)$, and a similar trend for males in their $50 \mathrm{~s}(\beta=0.10 ; \mathrm{P}=0.052, \mathrm{~d}=0.15$, $R^{2}=0.023\left[\Delta R^{2}=0.006\right.$, not statistically significant $\left.\left.(n s)\right]\right)$ and 70 s $\left(\beta=0.09 ; P=0.022, d=0.19, R^{2}=0.014\left[\Delta R^{2}=0.007, n s\right]\right)$. In contrast, an inverse group difference emerged for male patients in their $80 \mathrm{~s}$ who cohabit with paid help, such that they reported lower pain interference than same-age males who live alone $(\beta=-0.08 ; P=0.025$, $\left.\mathrm{d}=-0.71, \mathrm{R}^{2}=0.013\left[\Delta \mathrm{R}^{2}=0.007, \mathrm{~ns}\right]\right)$. In women, one set of significant differences emerged for patients in their 50s; compared with women who live alone, women who live with paid help reported lower pain interference $\left(\beta=-0.07 ; \mathrm{P}=0.052, \mathrm{~d}=-0.83, \mathrm{R}^{2}=0.022\left[\Delta \mathrm{R}^{2}=0.014\right.\right.$; $\mathrm{P}=0.045])$.

\section{Diagnostic subgroups}

To further examine the associations between coresidency patterns and pain interference, while accounting for patient condition, a series of follow-up analyses were conducted among patients with the most frequent diagnoses (ie, ICD-9 codes), separately, for the diagnostic subgroups with $\geq 30$ patients of each sex. These were designated by ICD-9 codes for diabetes; essential hypertension; chronic ischemic heart disease; congestive heart failure; peripheral vascular disease; pneumonia; chronic airway obstruction; disorders of urinary tract; cellulitis and abscess of leg; general muscle weakness; syncope and collapse, fainting, blackout; and abnormality of gait (see Table 1 for a breakdown of sample sizes and mean pain interference values). Some of the diagnoses are more chronic in nature (eg, chronic airway obstruction, diabetes) whereas others are more acute (eg, pneumonia and cellulitis), and it may be possible, for instance, that coresidence patterns have differential effects on pain reports depending on unique features of the disorders.

To retain as much data as possible, a variable was created to combine the previous dummy variables signifying coresidence with a friend, paid help or other help. These residential categories were the least reported and they tend to be less intimate than the other types of relationships (ie, significant other or family); this clustered group is 
TABLE 1

Mean pain interference levels of men and women with different diagnoses

\begin{tabular}{|c|c|c|c|c|}
\hline \multirow[b]{2}{*}{ Diagnosis } & \multicolumn{2}{|c|}{ Men } & \multicolumn{2}{|c|}{ Women } \\
\hline & $\mathbf{n}$ & Mean \pm SD & $\mathbf{n}$ & Mean \pm SD \\
\hline General muscle weakness & 194 & $0.96 \pm 1.04^{*}$ & 314 & $1.16 \pm 1.13^{*}$ \\
\hline Syncope and collapse, fainting, blackout & 39 & $0.97 \pm 0.96^{* \dagger}$ & 88 & $1.33 \pm 1.11^{* \dagger \ddagger}$ \\
\hline Diabetes & 101 & $1.06 \pm 1.00^{* \ddagger}$ & 105 & $1.00 \pm 1.05^{*}$ \\
\hline Chronic airway obstruction & 73 & $1.10 \pm 1.10^{\star \star \ddagger \S}$ & 128 & $1.29 \pm 1.04^{* \dagger \neq}$ \\
\hline Disorders of the urinary tract & 56 & $1.13 \pm 1.08^{\star \dagger \pm \S \pi}$ & 77 & $0.99 \pm 1.05^{*}$ \\
\hline Essential hypertension & 121 & $1.30 \pm 0.98^{\star \dagger+\$ \pi * \star \dagger \dagger}$ & 166 & $1.42 \pm 1.05^{\star \dagger \ddagger}$ \\
\hline Cellulitis and abscess of leg & 97 & $1.54 \pm 0.95 \S \pi * * \dagger+\neq \pm \S \S$ & 93 & $1.56 \pm 0.99 \dagger \neq \S$ \\
\hline Chronic ischemic heart disease & 417 & $1.58 \pm 0.84 \dagger \dagger \pm \ddagger \S \S$ & 145 & $1.66 \pm 0.89 \neq \S$ \\
\hline Abnormality of gait & 180 & $1.83 \pm 0.77 \S \S$ & 201 & $1.80 \pm 0.87 \S$ \\
\hline Peripheral vascular disease & 61 & $1.95 \pm 0.62 \S \S$ & 35 & $1.83 \pm 0.57 \ddagger \S$ \\
\hline
\end{tabular}

Different superscript symbols indicate within-sex group differences in pain interference for individuals with different primary diagnoses after using a Bonferroni adjustment for multiple comparisons

\section{TABLE 2}

Proportions of variance accounted for and beta coefficients for each residency category when predicting pain interference from residency, age and behaviour risk, separately for men and women with different diagnoses

\begin{tabular}{|c|c|c|c|c|c|c|c|c|}
\hline \multirow[b]{3}{*}{ ICD-9 } & \multirow[b]{3}{*}{ Male $\Delta R^{2}$} & \multirow[b]{3}{*}{ Female $\Delta R^{2}$} & \multicolumn{6}{|c|}{ Coresident partners } \\
\hline & & & \multicolumn{2}{|c|}{ Significant other } & \multicolumn{2}{|c|}{ Family } & \multicolumn{2}{|c|}{ Nonfamily } \\
\hline & & & Men & Women & Men & Women & Men & Women \\
\hline Chronic ischemic heart disease & $0.008(\mathrm{~ns})$ & $0.060^{* *}$ & 0.12 & 0.10 & 0.09 & $0.31^{* *}$ & 0.07 & 0.08 \\
\hline Chronic airway obstruction & $0.023(\mathrm{~ns})$ & $0.066^{* *}$ & 0.07 & $0.21^{* *}$ & 0.16 & 0.11 & -0.05 & -0.14 \\
\hline Disorders of the urinary tract & $0.009(\mathrm{~ns})$ & $0.089^{*}$ & -0.09 & $-0.32^{* *}$ & 0.01 & -0.27 & -0.06 & 0.11 \\
\hline Syncope and collapse, fainting, blackout & $0.179^{*}$ & $0.026(n s)$ & 0.37 & -0.07 & $0.55^{\star \star *}$ & -0.09 & 0.12 & -0.15 \\
\hline Abnormality of gait & $0.035^{*}$ & $0.004(\mathrm{~ns})$ & $0.25^{\star *}$ & 0.06 & 0.06 & 0.06 & 0.05 & -0.03 \\
\hline
\end{tabular}

The International Classification of Diseases, Ninth Revision (ICD-9) diagnostic codes are chronic ischemic heart disease (414.00); chronic airway obstruction (496.00); disorders of urethra (599.00); syncope and collapse, fainting, blackout (780.20); and abnormality of gait (781.20). The first set of columns represents the proportion of variance in pain interference accounted for by the three dummy-coded housemate variables for each sex, after controlling for patient age and behavioural risk factors. The remainder of the values shows standardized beta coefficients for the terms in the full models that correspond to coresidence with a significant other, a family member and someone else, respectively, using living alone as the reference category. ${ }^{*} P<0.10 ;{ }^{* *} P<0.05 ;{ }^{* * *} P<0.01$. ns Not statistically significant

hereafter referred to as coresidence with a nonfamilial person. For men and women separately in each diagnostic group, pain interference was simultaneously regressed on the three codes for housemates (significant other, other family member or nonfamilial person, with living alone as the reference group), and age and behavioural risk were entered as covariates. Of these, seven codes showed no significant main effects for the equations pertaining to the three housemate variables after entering age and behavioural risk as covariates (all $\mathrm{P}>0.05$ ). As shown in Table 2, the remainder of the diagnostic groups showed a significant difference between one of the housemate categories and the reference category (living alone) in men or women. The housemate variables accounted for a modest proportion of variance in pain interference and, in men, there was a general association between coresidence with a significant other $(\mathrm{d}=0.64)$ or other family member $(\mathrm{d}=1.72)$ and higher pain reports in men with abnormality of gait and syncope/ fainting/blackout/collapsing disorders, respectively. In women, the findings were somewhat more mixed, such that coresidence with a significant other or other family member was associated with higher pain reports in women with chronic airway obstruction $(\mathrm{d}=0.36)$ and chronic ischemic heart disease $(\mathrm{d}=0.76)$, respectively, and lower pain reports in women with a urethral disorder $(\mathrm{d}=-0.63)$.

\section{DISCUSSION}

The current study contributes to the extant research on social interactions, clinical pain experiences and other health outcomes $(6,9,35)$ by showing support for the possibility that coresidence patterns, in and of themselves, may partly influence activity-interfering pain levels in some home health care patients. Among the entire sample of home care patients, coresidence with an intimate relationship partner (eg, spouse) was associated with slightly greater pain interference than living alone, and this effect was moderated by patient sex. Male patients, and particularly those in their 30s, showed greater pain interference when living with a spouse or other romantic partner compared with living alone (although the statistical magnitudes of these effects were generally small, as discussed in more detail below). Across patient subgroups, the link between coresidence with a significant other and/or family and higher pain reports among men were most evident for patients with a primary diagnosis of syncope and collapsing, fainting, blackout and for patients with gait abnormalities. Female patients, particularly women in their 50s, showed a related pattern of slightly higher pain interference when living with a family member and lower pain interference when living with paid help, compared with living alone; however, the (generally modest) magnitude of these effects varied widely according to patient diagnoses. Thus, while previous research has shown that social integration may attenuate overall mortality risk (11), the current study suggests that coresidence with intimate types of affiliates may also be associated with a slight increase in the risk of experiencing clinically relevant pain for some people.

These observations are broadly consistent with a 'social signalling' perspective of human pain behaviours and the general thesis that patient pain experiences are influenced by the social environment in which pain is expressed $(22-26,28,29)$. Previous research shows that chronic pain patients with solicitous spouses report greater pain behaviours $(14,19)$ and, in the current study, we found that merely living with a family member or a significant other is associated with slightly higher pain reports than living alone or living with a less 
intimate affiliate (eg, nonfamily member). Other research shows that the association between pain catastrophizing and sensory pain is stronger for individuals who live with a romantic partner compared with individuals who live with someone else (36), which is also consistent with the social-signalling view of pain behaviours. Similarly, because women tend to express higher pain empathizing and related demonstrations of solicitude than men $(26,27,37,38)$, it is possible that individuals with more frequent interactions with female confidantes, such as girlfriends and wives, may experience slightly heightened pain levels than individuals without such interactions $(26,29)$. An indirect examination of this possibility, via estimating the effect of living with a romantic partner separately for men and women, yielded mixed findings. When the entire sample was considered, only men reported the tendency to show slightly higher pain interference when living with a romantic partner, yet this effect was also found for women with chronic airway obstruction. The reverse pattern of lower pain interference among women who live with a significant other was instead found for women with disorders of the urethra tract. Hypothetically, it is possible that women generally tend to exhibit a similar pattern as that of male patients (though perhaps to varying degrees [31]), particularly with illnesses that are more chronic in nature (eg, chronic ischemic heart disease, chronic airway obstruction), whereas the opposite pattern may be observed (hypoalgesia among intimate confidantes) for certain medical conditions that may be more acute, socially distressing or embarrassing.

Finally, a discussion of the study's limitations is warranted. First, because the home care clinicians are prohibited from interpreting or otherwise altering the documentation of patient pain functioning, the accuracy of the pain measurement is dependent on the timeliness of completion and patient-generated, subjective self-reports. Future research should incorporate both quantitative and qualitative data that includes patient interviews that can verify patient reports ("Can you walk to the bathroom, Mrs Jones?") and observational measures of pain experiences and pain-related activity ("Show me how you get to the bathroom"). Additional studies should also account for factors known to correspond with pain experiences, including comorbid illnesses, neuropsychiatric conditions, race, culture, education, work status and disability status, among others. Although we attempted to control for group differences in pain severity attributable to patient diagnosis, the single item used to establish the degree to which patients experienced activity-interfering pain did not differentiate whether the interference was caused by pain or from the illness. It is also unclear how some of the patient diagnoses examined in the current study, such as syncope/fainting/blackouts/collapsing, may have contributed to pain interference in and of themselves, compared with, for example, peripheral vascular disease (which may be associated with mechanical and neuropathic pain mechanisms). One possibility is that the reported pain may be associated with fear and uncertainty or painrelated catastrophizing in patients who experience certain symptoms such as sudden loss of consciousness.

Additionally, some of the omnibus analyses could have been overpowered statistically, while some of the more discrete analyses (eg, across patient diagnoses) may have been underpowered. Similarly, some of the statistically significant findings with small effect sizes may have limited clinical relevance, particularly given the limited amount of variance accounted for by the variables in many of the analyses. It may be noted, however, that we focused mainly on categorical variables (type of relationship with housemate, sex), and that such variables cannot explain as much variance as more classical continuous predictors. This is because every individual in a given category is assigned the same value on the predictor (and, hence, the same predicted value), while two individuals rarely have the exact same value on a continuous predictor (eg, age). In other words, prediction based on categorical variables is performed at the group level instead of the individual level, which limits the amount of variance categorical variables can explain. Also, small proportions of variance can be misleading. Abelson (39) has shown that the proportion of variance shared between a continuous variable and a dichotomous variable can be very small, even for a situation in which one would expect the proportion of variance shared to be large (eg, the proportion of variance shared between a baseball batter's batting average and a dichotomous variable indicating whether a batter would hit the ball or not on a given pitch, which is $<0.001$ ). Abelson (39) explains that even such a minuscule proportion of variance can be meaningful, provided that this small effect can make itself felt over time, and given that there are nearly infinite additional factors that could have influenced any particular outcome variable. In the current study, we found that patients differed in the amount of pain interference they experience daily depending on who they live with (among other predictors). Surely, slight differences in pain interference experienced on a daily basis matter much to the patients concerned. Therefore, the small proportion of variance explained in our models may be the misleading result of a statistical artifact and may still be indicative of meaningful differences among (and for) patients.

Another consideration is that although patients are often alone when the OASIS comprehensive assessment is completed, some of the patients undoubtedly reported their pain interference in the presence of a caregiver. Therefore, it is possible that pain reports could be biased in some patients due to the comfort (or lack thereof) of reporting painrelated behavioural functioning in the presence of different affiliates. It is also possible that other psychosocial factors, such as structural and functional components of patients' social networks, more widely interact with characteristics of the patient's home environment to influence various aspects of pain behaviours. Another possibility is that some of the findings were influenced by patient selection issues and differential use of home health care services, potentially limiting the generalizability of the findings and further contributing to the variable effect sizes observed in the study. Finally, it is likely that some patients' health conditions influenced their living environment and the type of personal care they received. Although the current data were collected on patient intake for home care services, it remains true that future longitudinal and experimental studies are required to examine how social environmental factors (eg, residential patterns, peer network dynamics, situational context) may actually induce changes in clinical pain experiences.

Taking these potential limitations into consideration, the current findings are significant for showing that a very basic, objective and easily assessable component of patients' home-living environment may have a slight influence on patient pain functioning in some individuals. That is, while cohabitating with different types of relationship partners and potential caregivers presumably enhances patients' chances for general medical improvement in many ways, such as providing logistical support and treatment advocacy, it may also result in some unintended consequences that potentially influence patient debilitation to some degree. These findings have practical, clinical relevance for treating, managing and formulating a care plan for patients by guiding differential needs assessments and patient awareness. Patient awareness may be particularly relevant for subgroups of patients (eg, young men) with unique relationship experiences and pressures (eg, to mate and have children), which may precipitate the tendency for significant others to demonstrate heightened solicitous reactions toward the individual experiencing pain (potentially affecting patient pain experiences). Complementary research investigating how patients' caregivers are reciprocally affected (psychologically and behaviourally) by characteristics of their patients may also be warranted (25). Nonetheless, the tendency for health assessors to discount patient pain experiences in the absence of medical explanations of the pain (40) makes it especially important to understand how psychosocial factors, such as environmental and situational effects (eg, characteristics of medical examiners $[22,41,42])$, contribute to how patients experience and report their pain.

AUTHOR CONTRIBUTIONS: J Vigil and P Pendleton designed the study; P Coulombe assisted with data analyses; and K Vowles, J Alcock and B Smith assisted with data interpretation and presentation. All the authors discussed the findings and commented on the manuscript. 


\section{REFERENCES}

1. Bergman S. Psychosocial aspects of chronic widespread pain and fibromyalgia. Disabil Rehabil 2005;27:675-83.

2. Cheng C, Wong W, Lai K, et al. Psychosocial factors in patients with noncardiac chest pain. Psychosom Med 2003;65:443-9.

3. Evers AW, Kraaimaat FW, Geene R, Jacobs JW, Bijlsma JW. Pain coping and social support as predictors of long-term functional disability and pain in early rheumatoid arthritis. Behav Res Ther 2003;41:1295-310.

4. Gil KM, Keefe FJ, Crisson JE, Van Dalfsen PJ. Social support and pain behavior. Pain 1987;29:209-17.

5. Lauver SC, Johnson JL. The role of neuroticism and social support in older adults with chronic pain behavior. Pers Individ Dif 1997;23:165-7.

6. López-Martínez AE, Esteve-Zarazaga R, Ramírez-Maestre C. Perceived social support and coping responses are independent variables explaining pain adjustment among chronic pain patients. J Pain 2008;9:373-9.

7. Montoya P, Larbig W, Braun C, Preissl H, Birbaumer N. Influence of social support and emotional context on pain processing and magnetic brain responses in fibromyalgia. Arthritis Rheumatism 2004;50:4035-44.

8. Stanke KM, Ivanec D. Social context of pain perception: The role of other people's presence and physical distance. Rev Psychol 2010;17:69-74.

9. Uchino BN. Social support and health: A review of physiological processes potentially underlying links to disease outcomes. J Behav Med 2006;29:377-87.

10. Zhou X, Gao D. Social support and money as pain management mechanisms. Psychol Inq 2008;19:127-44.

11. Holt-Lunstad J, Smith TB, Layton JB. Social relationships and mortality risk: A meta-analytic review. PLoS Med 2010;7:e1000316.

12. Block AR, Kremer EF, Gaylor M. Behavioral treatment of chronic pain: The spouse as a discriminative cue for pain behavior. Pain 1980;9:243-52.

13. Cano A, Barterian JA, Heller JB. Empathic and nonempathic interaction in chronic pain couples. Clin J Pain 2008;24:678-84.

14. Flor H, Kerns RD, Turk DC. The role of spouse reinforcement, perceived pain, and activity levels of chronic pain patients. J Psychosom Res 1987;31:251-9.

15. Fillingim RB, Doleys DM, Edwards RR, Lowery D. Spousal responses are differentially associated with clinical variables in women and men with chronic pain. Clin J Pain 2003;19:217-24.

16. Kerns RD, Rosenberg R, Otis JD. Self-appraised problem solving and pain-relevant social support as predictors of the experience of chronic pain. Ann Behav Med 2002;24:100-5.

17. Newton-John TR. Solicitousness and chronic pain: A critical review. Pain Rev 2002;9:7-27.

18. Romano JM, Turner JA, Jensen MP, et al. Chronic pain patientspouse behavioral interactions predict patient disability. Pain 1995;63:353-60.

19. Romano JM, Jensen MP, Turner JA, Good AB, Hops H. Chronic pain patient-partner interactions: Further support for a behavioral model of chronic pain. Behav Ther 2000;31:415-40.

20. Romano JM, Jensen MP, Schmaling KB, Hops H, Buchwald DS. Illness behaviors in patients with unexplained chronic fatigue are associated with significant other responses. J Behav Med 2009;32:558-69.
21. McClelland LE, McCubbin JA. Social influence and pain response in men and women. J Behav Med 2008;31:413-20.

22. Vigil JM, Coulombe P. Sex and audience affects pain intensity and observational coding of other people's pain behaviors. Pain 2011;152:2125-30.

23. Craig KD. The social communication model of pain. Can Psychol 2009;50:22-32.

24. Craig KD, Versloot J, Goubert L, Vervoort T, Crombez G. Perceiving pain in others: Automatic and controlled mechanisms. J Pain 2010;11:101-8.

25. Hadjistavropoulos T, Craig KD, Duck S, et al. A biopsychosocial formulation of pain communication. Psychol Bull 2011;137:910-39.

26. Vigil JM. A socio-relational framework of sex differences in the expression of emotion. Behav Brain Sci 2009;32:375-90.

27. Vigil JM. The socio-relational framework of expressive behaviors as an integrative psychological paradigm. Behav Brain Sci 2009;32:408-28.

28. Williams A. Facial expression of pain: An evolutionary account. Behav Brain Sci 2002;25:439-88.

29. Vigil JM, Strenth C. No pain, no social gains: A social-signaling perspective of human pain behaviors. World J Anesthesiol; In press.

30. Flor H, Turk DC, Rudy TE. Relationship of pain impact and significant other reinforcement of pain behaviors: The mediating role of gender, marital status and marital satisfaction. Pain 1989;38:45-50.

31. Vigil JM, Rowell N, Chouteau S, et al. Sex differences in how social networks and relationship quality influence experimental pain sensitivity. PLoS ONE 2013;8:e78663.

32. Centers for Medicare \& Medicaid Services. CMS OASIS. <www. cms.hhs.gov/oasis/> (Accessed April 2013).

33. Madigan EA, Fortinsky RH. Additional psychometric evaluation of the Outcomes and Assessment Information Set (OASIS). Home Health Care Serv Q 2000;18:49-62.

34. Cohen J. Statistical Power Analysis for the Behavioral Sciences, 2nd edn. Hillsdale: Lawrence Erlbaum, 1988.

35. Vowles KE, Cohen LL, McCracken LM, Eccleston C. Disentangling the complex relations among caregiver and adolescent responses to adolescent chronic pain: A cross-sectional, multivariate analysis using structural equation modelling. Pain 2010;151:680-6.

36. Giardino ND, Jense MP, Turner JA, Ehde DM, Cardenas DD. Social environment moderates the association between catastrophizing and pain among persons with a spinal cord injury. Pain 2003;106:19-25.

37. Vigil JM. Asymmetries in the social styles and friendship preferences of men and women. Hum Nat 2007;18:143-61.

38. Vigil JM. Sex differences in affect behaviors, desired social responses, and accuracy at understanding the social desires of other people. Evol Psychol 2008;6:506-22.

39. Abelson RP. A variance explanation paradox: When a little is a lot. Psychol Bull 1985;97:129-33.

40. Ruddere L, Goubert L, Vervoort T, Prkachin KM, Crombez G. We discount the pain of others when pain has no medical explanation. J Pain 2012;13:1198-205.

41. Vowles KE, McNeil DW, Sorrell JT, Lawrence SM. Fear and pain: Investigating the interaction between aversive states. J Abnorm Psychol 2006;115:821-33.

42. Vigil JM, Alcock J. Tough guys or sensitive guys? Disentangling the role of examiner gender on patient pain reports. Pain Res Manag 2014;19:e9-e12. 


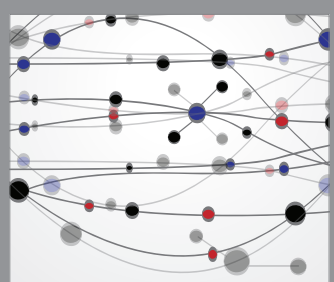

The Scientific World Journal
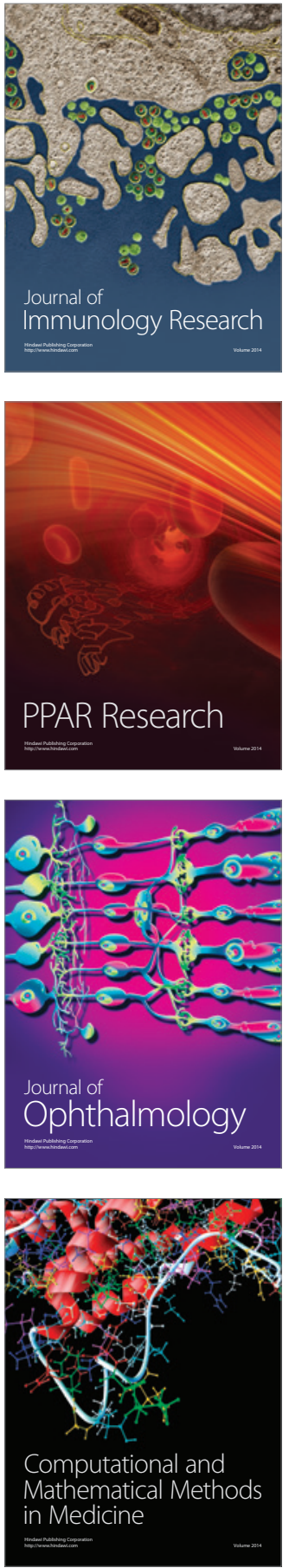

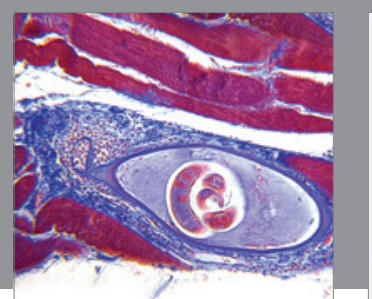

Gastroenterology Research and Practice

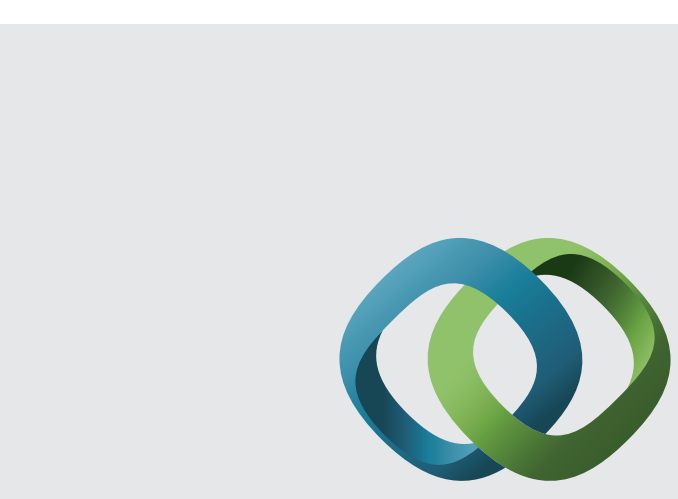

\section{Hindawi}

Submit your manuscripts at

http://www.hindawi.com
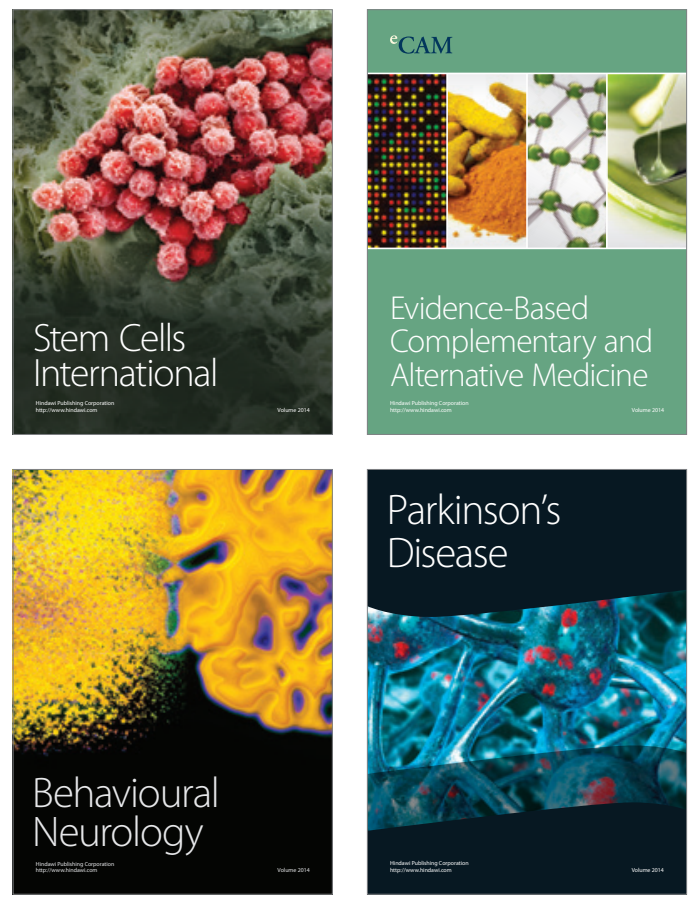
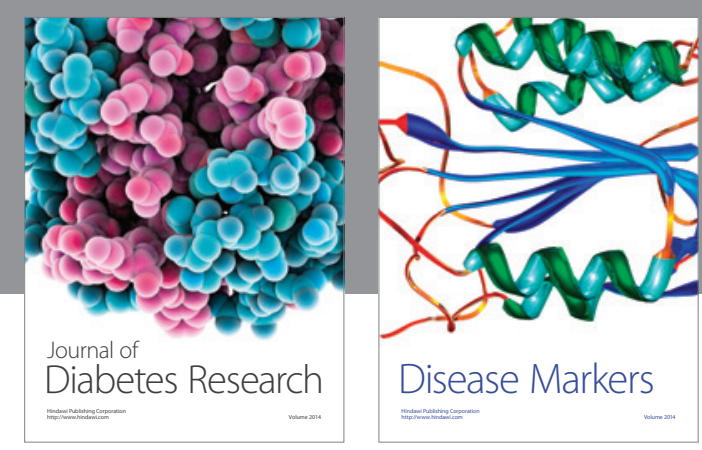

Disease Markers
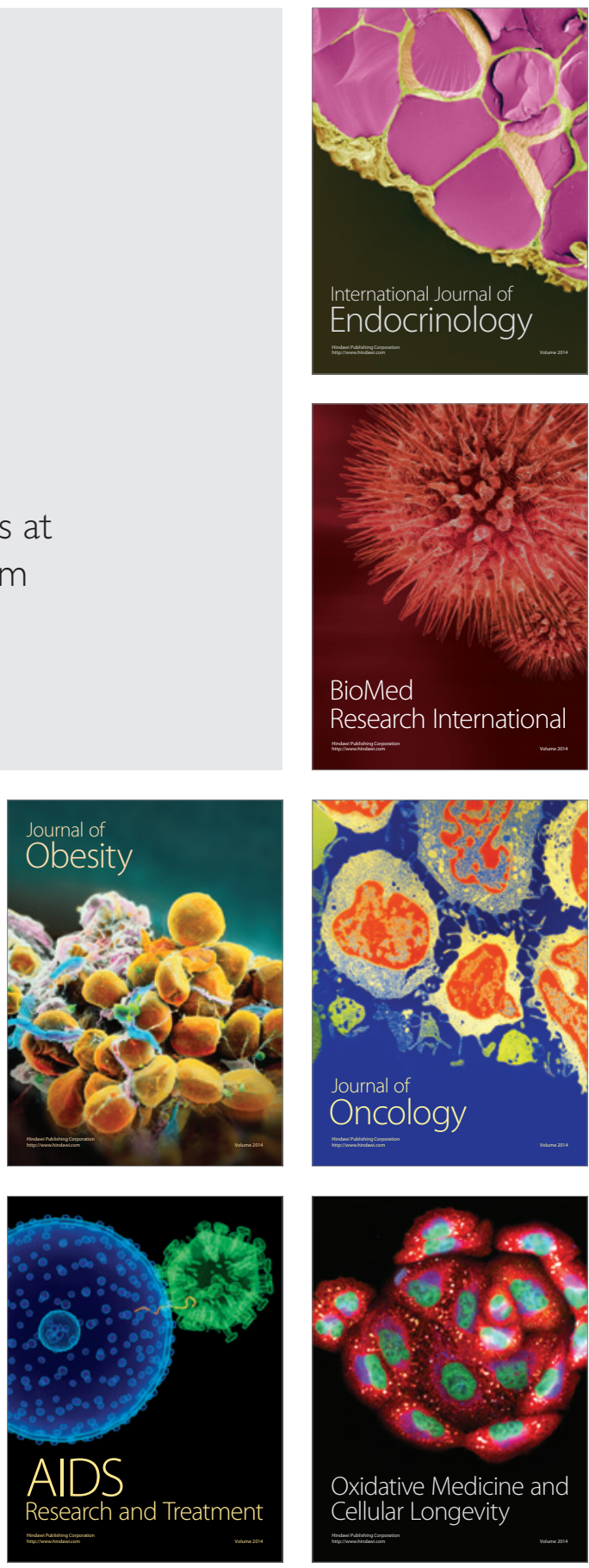